\title{
Pullulan/Poly(Vinyl Alcohol) Composite Hydrogels for Adipose Tissue Engineering
}

\author{
Iuliana Samoila ${ }^{1,+}+{ }^{+}$, Sorina Dinescu $1,+\left(\mathbb{D}\right.$, Gratiela Gradisteanu Pircalabioru ${ }^{2,3, *}$, \\ Luminita Marutescu ${ }^{2}$, Gheorghe Fundueanu ${ }^{4}$, Magdalena Aflori ${ }^{4}$ (D) and Marieta Constantin ${ }^{4, *}$ \\ 1 Department of Biochemistry and Molecular Biology, University of Bucharest, 91-95 Splaiul Independentei, \\ 050095 Bucharest, Romania; iuliana.samoila@bio.unibuc.ro (I.S.); sorina.dinescu@bio.unibuc.ro (S.D.) \\ 2 Research Institute of University of Bucharest, University of Bucharest, 050107 Bucharest, Romania; \\ lumi.marutescu@gmail.com \\ 3 Sanimed International IMPEX SRL, Sos. București Măgurele 70F, 051434 Bucharest, Romania \\ 4 Department of Natural Polymers, Bioactive and Biocompatible Materials, Institute of Macromolecular \\ Chemistry, 700487 Iassy, Romania; gfundeanu@icmpp.ro (G.F.); maflori@icmpp.ro (M.A.) \\ * Correspondence: gratiela.gradisteanu@icub.unibuc.ro (G.G.P.); marieta@icmpp.ro (M.C.); \\ Tel.: +40-727-668-664 (G.G.P.); +40-232-217-454 (M.C.) \\ + These authors have equal contribution.
}

Received: 2 September 2019; Accepted: 28 September 2019; Published: 1 October 2019

\begin{abstract}
Composite hydrogels based on pullulan (HP) and poly(vinyl alcohol) (PVA) were both prepared by simple chemical crosslinking with sodium trimethaphosphate (STMP) or by dual crosslinking (simultaneously chemical crosslinking with STMP and physical crosslinking by freeze-thaw technique). The resulting hydrogels and cryogels were designed for tissue engineering applications. PVA, with two different molecular weights $(47,000$ and 125,000 g/mol; PVA 47 and $\mathrm{PVA}_{125}$, respectively), as well as different P/PVA weight ratios were tested. The physico-chemical characterization of the hydrogels was performed by FTIR spectroscopy and scanning electron microscopy (SEM). The swelling kinetics, dissolution behavior, and degradation profiles in simulated physiological conditions (phosphate buffer at $\mathrm{pH}$ 7.4) were investigated. Pullulan concentration and the crosslinking method had significant effects on the pore size, swelling ratio, and degradation profiles. Cryogels exhibit lower swelling capacities than the conventional hydrogels but have better stability against hydrolitic degradation. Biocompatibility of the hydrogels was also investigated by both MTT (3-(4,5-dimethylthiazol-2-yl)-2,5-diphenyltetrazolium bromide) and LDH (lactaten dehydrogenase) assay. The MTT and LDH assays proved that dual crosslinked HP/PVA 125 (75:25, $w / w)$ scaffolds are more biocompatible and promote to a greater extent the adhesion and proliferation of L929 murine fibroblast cells than chemically crosslinked HP/PVA 47 (50/50, w/w) scaffolds. Moreover, the HP/PVA 125 cryogel had the best ability for the adipogenic differentiation of cells. The overall results demonstrated that the HP/PVA composite hydrogels or cryogels are suitable biomaterials for tissue engineering applications.
\end{abstract}

Keywords: hydrogels; poly(vinyl alcohol) (PVA); pullulan; scaffolds; adipose tissue engineering

\section{Introduction}

Modern healthcare constantly has to deal with an increased number of patients with high-grade burns or patients who need tissue reconstruction after tissue loss or tumor removal [1]. The first attempts at replacing damaged tissue were made using techniques based on autologous or allogenic transplants or with soft tissue fillers [2]. These techniques are not always the best answer for the regeneration of severe adipose tissue defects because of the adverse effects they may cause, such as inflammation or structure deformation [3]. 
Therefore, adipose tissue engineering (ATE) has emerged as a method to overcome all these disadvantages. For ATE to be successful, there are two characteristics that need to be combined; a cell source able to differentiate towards adipogenic lineage and a tridimensional scaffold with an interconnected pore architecture, so that oxygen and nutrients can reach the cells [3,4]. Materials used in ATE have to be soft and easy to operate with, in order to minimize patient discomfort [5]. Furthermore, because of the highly vascularized adipose tissue, the biomaterial should support proper vascularization to ensure the transportation of vital elements for adipocytes; growth factors, cytokines, and hormones.

Hydrogel scaffolds are used to provide massive and mechanical structures for a tissue construct, whether the cells are suspended or adherent to the three-dimensional hydrogel. Hydrogels can be obtained from both synthetic [6] and natural [7] polymers by various methods such as physical, chemical gelation, or self-assembly. In the last years, hydrogels prepared from natural polymers, especially polysaccharides [8], have been widely used because of their hydrophilicity, biocompatibility, and low toxicity. Among them, pullulan $(\mathrm{P})$ has been increasingly studied in vascular and bone tissue engineering. Thus, porous scaffolds based on dextran and pullulan support the viability, proliferation, differentiation, and function of human endothelial cells isolated from heart blood [9] and composite hydroxyapatite/pullulan/dextran hydrogels induce cell differentiation in vitro and formation of mineralized bone tissue in vivo [10]. Collagen-pullulan composite scaffolds viably sustain in vitro human fibroblasts and murine mesenchymal stem cells and endothelial cells [11].

On the other hand, poly(vinyl alcohol) (PVA)-based hydrogels are promising candidates for tissue engineering applications. PVA is a biosynthetic polymer, biocompatible and non-toxic, with a great ability to form hydrogels either through chemical or physical crosslinking. While chemical crosslinking with radiation or aldehydes provides greater control over the final properties of the hydrogel, physically crosslinked hydrogels, or blends with other biocompatible polymers (dextran [12,13], starch [14], chitosan [15,16], alginates [17-19], gelatin [20,21], poly(vinyl pirrolidone) [22] (are more suitable candidates for biomedical applications. Scaffolds based on PVA were proposed for long-term culture of hepatocytes and mesenchymal stem cells [23-25].

Human adipose-derived stem cells (hASCs) represent a population of mesenchymal stem cells, which can be easily isolated from liposuction aspirate and cultured. They are often used in tissue engineering applications because of their tendency to differentiate into pre-adipocytes [3,4].

Adipocytes' cytoplasm contains a large number of lipid droplets, which have a major importance in cellular lipid homeostasis by storing triacylglycerols [26]. Lipid droplets have an external phospholipid monolayer of lipid droplet proteins, including perilipin. Perlipin is a key component in lipid storage and is the most common protein found on the surface of lipid droplets [27] (Sawada et al., 2010). Perilipin is of great interest when evaluating adipogenesis, because its expression is higher when preadipocytes differentiate into adipocytes [28].

As seen in the literature, both P [29,30] and PVA [31] suffer chemical crosslinking with trisodium trimethaphosphate (TMP), a non-toxic cyclic triphosphate crosslinking agent already used in hydrogel synthesizing for pharmaceutical uses. Since the chemical crosslinked PVA presents poor elasticity and resistance [32] we propose a combining method of chemical agent and freeze-thawing cycles for obtaining composite HP/PVA hydrogels with a high hydration degree and good mechanical properties. The hydrogels were characterized in terms of swelling ratio and dissolution behavior. Finally, biocompatibility and adipogenic differentiation ability of the novel hydrogels were assessed.

\section{Materials and Methods}

\subsection{Materials}

Pullulan $(\mathrm{P})(\mathrm{Mw}=200,000 \mathrm{~g} / \mathrm{mol})$ was purchased from Hayashibara Lab. Ltd. (Okoyama, Japan). Poly(vinyl alcohol) ( $\mathrm{PVA}_{125}$ ) (average $\mathrm{Mw} \sim 125,000 \mathrm{~g} / \mathrm{mol}$, degree of hydrolysis 98.0-98.8 $\mathrm{mol} \%$ ), $\left(\mathrm{PVA}_{47}\right.$ ) (average $\mathrm{Mw} \sim 47,000 \mathrm{~g} / \mathrm{mol}$, degree of hydrolysis $98.0-98.8 \mathrm{~mol} \%$ ), 
trisodium trimethaphosphate p.a. (STMP), and sodium hydroxide p.a. $(\mathrm{NaOH})$ were purchased from Sigma-Aldrich Chemie GmbH, Steinheim, Germany.

\subsection{Methods}

\subsubsection{Preparation of HP/PVA Crosslinked Composite Hydrogels}

Composite HP/PVA hydrogels were obtained by crosslinking reaction of the two components with STMP in alkaline conditions. Firstly, $10 \%(w / v) \mathrm{PVA}_{47}$ or $5 \%(w / v) \mathrm{PVA}_{125}$ aqueous solutions were prepared by heating at $90{ }^{\circ} \mathrm{C}$ for 1 hour under magnetic stirring. Then, the corresponding amount of pullulan was added so as to obtain the gravimetric ratio between the two polymers shown in Table 1 . The solution was cooled to room temperature, then $1 \mathrm{~mL}$ of $10 \mathrm{M} \mathrm{NaOH}$ and $5 \mathrm{~mL}$ of a $10 \%(w / v)$ STMP aqueous solution were added. The solution was kept under vigorous stirring for several minutes after which it was poured into $6 \mathrm{~cm}$ diameter petri dishes. Finally, the solutions were either subjected to the freezing-thawing process with 3 cycles of 20 hours at $20^{\circ} \mathrm{C}$ and 6 hours at room temperature or were maintained at room temperature $\left(\sim 23 \pm 1{ }^{\circ} \mathrm{C}\right)$ for the same time (Table 1). At the end of the cycles, the disc hydrogels were extensively washed with distilled water then recovered by lyophilization $\left(57^{\circ} \mathrm{C}, 5.5 \times 10^{-4} \mathrm{mbar}\right)$ using a lyophilizer ALPHA 1-2 LD, Christ, Germany. The sample codes are HP/PVAx-R or HP/PVAx-F, where P means pullulan, PVA is poly(vinyl alcohol), $x=$ molecular mass of $\mathrm{PVA}, \mathrm{R}$ and $\mathrm{F}$ refer to the crosslinking procedure used (room temperature $(\mathrm{R})$ or freeze-thawing $(\mathrm{F})$ ).

Table 1. Preparation conditions and phosphate groups content of HP/poly(vinyl alcohol) (PVA) composite hydrogels.

\begin{tabular}{|c|c|c|c|c|}
\hline \multirow{2}{*}{ Sample Code } & \multirow{2}{*}{$\begin{array}{l}\text { Composition } \\
\text { P/PVA (g \%) }\end{array}$} & \multicolumn{2}{|c|}{ Crosslinking Method } & \multirow{2}{*}{$\begin{array}{c}\text { Phosphate Groups } \\
\text { Content * } \\
\text { (mmol/g Hydrogel) }\end{array}$} \\
\hline & & Procedure & Method & \\
\hline $\begin{array}{c}\text { HP/PVA } \\
\text { 47-R } \\
\text { (average } \mathrm{Mw} \sim 47,000 \mathrm{~g} / \mathrm{mol} \text {, } \\
\text { crosslinked at room temp) }\end{array}$ & $50 / 50$ & $\begin{array}{c}\text { Room } \\
\text { temperature }\end{array}$ & chemical & $1.93 \pm 0.15$ \\
\hline $\begin{array}{c}\text { HP/PVA } 47-\mathbf{F} \\
\text { (average Mw } \sim 47,000 \mathrm{~g} / \mathrm{mol} \text {, } \\
\text { crosslinked by cryogelation) }\end{array}$ & $50 / 50$ & Cryogelation & $\begin{array}{c}\text { Chemical and } \\
\text { physical }\end{array}$ & $1.39 \pm 0.24$ \\
\hline $\begin{array}{c}\text { HP/PVA } 125-\mathbf{F} \\
\text { (average } \mathrm{Mw} \sim 125,000 \mathrm{~g} / \mathrm{mol}, \\
\text { crosslinked by cryogelation) }\end{array}$ & $75 / 25$ & Cryogelation & $\begin{array}{c}\text { Chemical and } \\
\text { physical }\end{array}$ & $1.73 \pm 0.26$ \\
\hline
\end{tabular}

* Determined by conductometric titration with $0.1 \mathrm{~N} \mathrm{HCl}$.

\subsubsection{FTIR Spectroscopy}

The spectra were recorded using a Bruker Vertex 7 FTIR spectrophotometer. The samples were analyzed in lyophilized state on a KRS-5 support, within the frequency range of $4000-600 \mathrm{~cm}^{-1}$. Data processing was done using the OPUS 6.5 software (Bruker Optik GmbH, Ettlingen, Germany).

\subsubsection{Morphology}

Morphological characterization was performed by scanning electron microscopy (SEM,) using an environmental scanning electron microscope (ESEM, FEI, Eindhoven, The Netherlands) type Quanta 200 , operating with secondary electrons in low vacuum at $20 \mathrm{kV}$.

\subsubsection{Swelling and Dissolution Behavior}

The swelling degree of the hydrogels was measured gravimetrically in phosphate buffer $\mathrm{pH} 7.4$ (PBS). The process involves immersing dry weighed hydrogels $\left(W_{\mathrm{d}}\right)$ in the swelling medium and weighing them at different time intervals $\left(W_{\mathrm{s}}\right)$ after they have been removed from the test medium 
and buffered lightly onto the surface with filter paper. The experiment was performed in triplicate and average values were reported. Swelling ratio (SR) was calculated according to Equation (1):

$$
S R=\frac{\left(W_{s}-W_{d}\right)}{W_{d}}
$$

The stability of HP/PVA hydrogels upon swelling in water was examined. Each sample of raw hydrogel $(\mathrm{d} \times \mathrm{h}=1 \cdot \times 5 \mathrm{~cm})$ was immersed in water for 3 days at room temperature $\left(23 \pm 1{ }^{\circ} \mathrm{C}\right)$. After that the samples were removed from the water and then the excess water and degraded polymer were removed from the surface of the hydrogels through blotting. Samples were weighed before and after immersion, and the dissolution percent (D \%) was calculated according to Equation (2) [33] (Abdel-Mohsen et al., 2011):

$$
D(\%)=\frac{W_{2}}{W_{1}} \times 100
$$

where $W_{2}$ and $W_{1}$ are the weight of the sample after and before extraction, respectively.

\subsubsection{In Vitro Degradation Studies}

Degradation of the hydrogel was evaluated by incubating dried samples $(2 \times 1 \mathrm{~cm})$ in PBS at $37^{\circ} \mathrm{C}$. The PBS solution was changed weekly. At pre-selected time points, the remaining hydrogels were removed from the buffer solution, washed with distilled water, lyophilized, and dried in a vacuum drier at $60^{\circ} \mathrm{C}$ to constant weight. The percent of weight loss (WL) of each sample was determined according to Equation (3):

$$
W L(\%)=\frac{\left(W_{0}-W_{t}\right)}{W_{0}} \times 100
$$

where $W_{0}$ and $W_{t}$ are the sample weights before and after degradation, respectively. All data were averaged from three measurements.

\subsubsection{Biocompatibility Studies}

All composite samples were sterilized by exposure to UV light for $24 \mathrm{~h}$, then the materials were put into contact with complete medium and cut into small pieces of $1 \mathrm{~cm}$ diameter. After 2 and 6 days of culture in standard conditions, L929 fibroblast cell viability and proliferation were assessed quantitatively by MTT test and qualitatively by Live/Dead staining and observation by confocal microscope. The three-dimensional cultures were incubated with $1 \mathrm{mg} / \mathrm{mL}$ MTT solution (Sigma-Aldrich Co, Steinheim, Germany) in culture media with no fetal bovine serum (FBS). After $4 \mathrm{~h}$ of incubation, formazan crystals were solubilized in isopropanol, resulting in a violet solution that was quantified by spectrophotometry at $550 \mathrm{~nm}$ using FlexStation3 (Molecular Devices, USA). Scaffold's cytotoxic effect on the cells was measured using an In Vitro Toxicology Assay Kit, Lactic Dehydrogenase based (Tox7 kit, Sigma-Aldrich) following the manufacturer's instructions. The final solution was assessed by spectrophotometric measurement at $490 \mathrm{~nm}$. Staining of live and dead cells in the three-dimensional cultures was performed following the manufacturer's protocol using a Live/Dead kit (ThermoFisher Scientific, Foster City, CA, USA). Composites were examined by confocal microscopy (Carl Zeiss LSM 710, Jena, Germany), and images were processed using Zeiss Zen 2010 software (2010 version, Carl Zeiss, Jena, Germany).

\subsubsection{Adipogenic Differentiation Assessment}

(1) Adipogenic marker perilipin gene expression analysis

Total RNA was extracted from the bioconstructs with TRIzol Reagent, and was then tested for purity and integrity by Agilent Bioanalyzer 2100. Reverstranscription was performed using a High Capacity cDNA Reverse Transcription Kit (ThermoFisher Scientific, Foster City, CA, USA) and final 
quantitative Real Time PCR(qPCR) was performed on the ViiA7 system using SYBR Green Master Mix (ThermoFisher Scientific, Foster City, CA, USA), following the manufacturer's instructions.

(2) Adipogenic marker perilipin protein expression

Cells were fixed using $4 \%$ paraformaldehyde solution (Sigma-Aldrich Co, Steinheim, Germany) for $2 \mathrm{~h}$ and then permeabilized for $2 \mathrm{~h}$ with $2 \%$ BSA/0.1\% Triton X-100 solution (Sigma-Aldrich Co., Steinheim, Germany). Bioconstructs were exposed overnight at $4{ }^{\circ} \mathrm{C}$ to rabbit polyclonal anti-perilipin antibody solution (1:100, Santa Cruz Biotechnology). The next day, secondary antibody goat anti-rabbit, coupled with AF546 (1:400, ThermoFisher Scientific, Foster City, CA, USA), was incubated for $2 \mathrm{~h}$ at room temperature, in darkness. Hoechst 33342 (ThermoFisher Scientific, Foster City, CA, USA) was used for 30 minutes to stain cell nuclei. Bioconstructs were observed using confocal microscopy (Carl Zeiss LSM 710, Jena, Germany) and images were analyzed with Zeiss Zen 2010 software. Quantification of fluorescent staining was performed by Image J software (version 1.52q, National Institutes of Health, Bethesda, Maryland, U.S.) and data is presented in percentage of area covered by red-labeled pixels.

\subsubsection{Statistical Analysis}

All experiments were performed in triplicate. Statistical analysis was performed using Graph Pad Prism software, one -way ANOVA method, and Bonferroni correction. Statistical significance was considered for $p<0.05$.

\section{Results and Discussion}

\subsection{Preparation and Characterization of HP/PVA Composite Hydrogels}

PVA has already been combined with P in applications in cosmetics and drug delivery [34,35]. Both polymers contain hydroxyl groups that can be easily chemically crosslinked with STMP. Moreover, supplementary crosslinking by cryogelation gives scaffolds improved hydrophilicity and mechanical strength. In alkaline conditions, the crosslinking reaction with STMP leads to the formation of biodegradable phosphoester bridges and phosphate pendant groups, negatively charged, favoring a high swelling in water [36,37]. The chemical crosslinking of the two polymers with STMP led to a transparent hydrogel (Figure 1A) whereas additional cryogelation generated opaque hydrogels (Figure 1B); a distinguishing sign for the physical crosslinking of PVA. The composition of HP/PVA hydrogels prepared by different crosslinking methods is presented in Table 1.
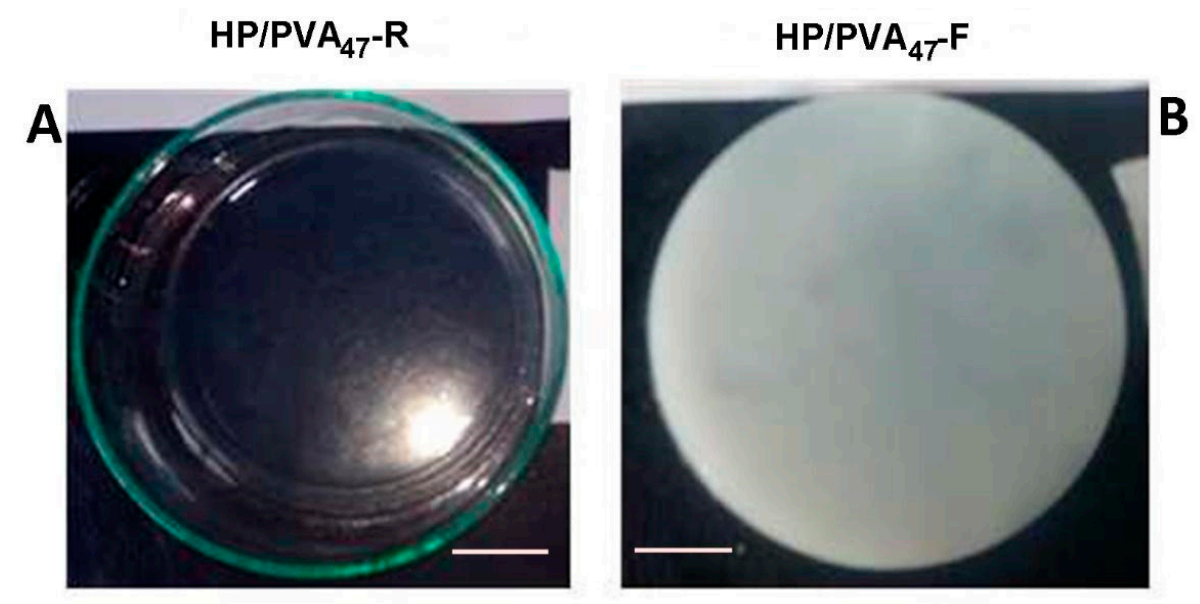

Figure 1. Optical images of $\mathrm{HP} / \mathrm{PVA}_{47}$ composite hydrogels obtained by chemical crosslinking at room temperature (panel A) and by combined procedure (chemical and freeze-thawing cycles) (panel B). Bar corresponds to $1 \mathrm{~cm}$. 


\subsubsection{Morphology}

SEM images of the internal structure of hydrogels obtained by chemical crosslinking with STMP and by supplementary crosslinking by cryogelation are presented in Figure 2. All types of hydrogels display a porous structure with interconnected pores. The size of the pores decreases from 30-55 $\mu \mathrm{m}$ for $\mathrm{HP} / \mathrm{PVA}_{47}-\mathrm{R}$ to $15-30 \mu \mathrm{m}$ for $\mathrm{HP} / \mathrm{PVA}_{47}-\mathrm{F}$ and $\mathrm{HP} / \mathrm{PVA}_{125}-\mathrm{F}$. In fact, the freezing-thawing procedure induced the crystallization of the polymeric chains of PVA and resulted in a denser network structure, which act as a physical crosslinker. However, through the freeze-thaw technique, there were non-homogeneous networks with areas where PVA can be assumed to be concentrated due to its physical crosslinking (Figure 2, $\mathrm{HP} / \mathrm{PVA}_{47}-\mathrm{F}$ and $\mathrm{HP} / \mathrm{PVA}_{125}-\mathrm{F}$ ).
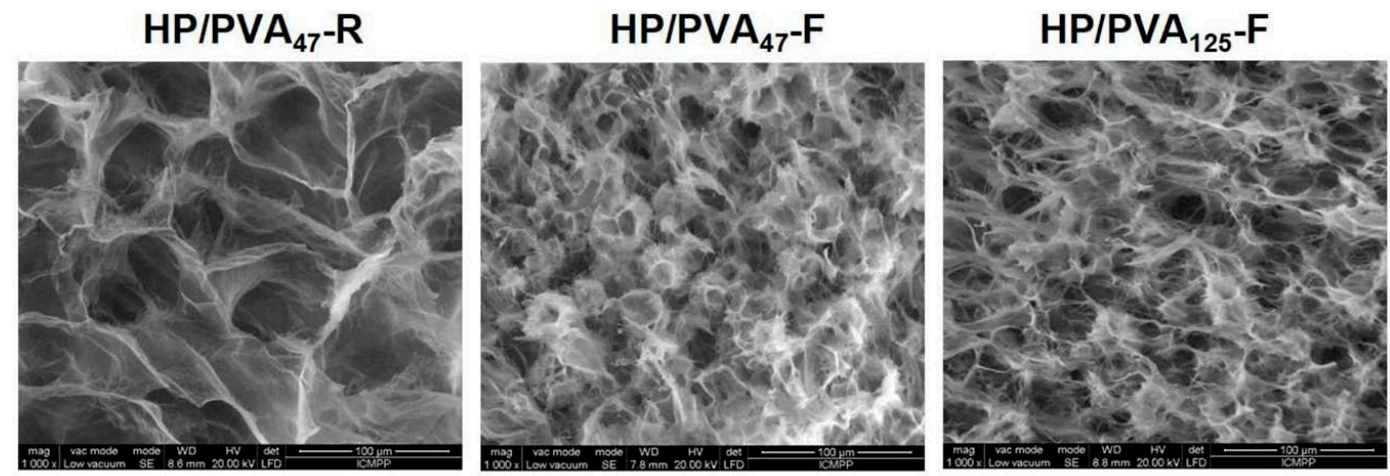

Figure 2. SEM microphotographs of the internal structure of composite hydrogels obtained by chemical crosslinking with STMP at room temperature $\left(\mathrm{HP} / \mathrm{PVA}_{47}-\mathrm{R}\right)$ and by combined procedure (chemical and freeze-thawing cycles) $\left(\mathrm{HP} / \mathrm{PVA}_{47}-\mathrm{F}\right.$ and $\left.\mathrm{HP} / \mathrm{PVA}_{125}-\mathrm{F}\right)$.

\subsubsection{Chemical Structure}

Crosslinking with STMP, and therefore the presence of phosphate groups in the HP/PVA hydrogels, was revealed by Fourier transform infrared spectrometry (FTIR). In Figure 3, the infrared spectra of native PVA and HP/PVA hydrogels prepared by the two techniques are presented and compared. The FTIR spectrum of the native PVA exhibits the typical stretch band of the inter- and intra-molecular $\mathrm{OH}$ groups at $3430 \mathrm{~cm}^{-1}$, the stretching bands corresponding to the symmetrical and asymmetric $\mathrm{CH}_{2}$ bonds at 2928 and $2855 \mathrm{~cm}^{-1}$, respectively, and a band at approximately $1720 \mathrm{~cm}^{-1}$, which can be attributed to the presence of the acetoxy group [38]. The IR spectrum of HP/PVA hydrogels shows the presence of the absorption bands characteristic of the two polymers but also the appearance of new bands, confirming crosslinking with STMP. Thus, the inter- and intra-molecular bonds in which the $\mathrm{OH}$ groups are involved are evidenced by the presence of the band at $3300 \mathrm{~cm}^{-1}$, and the new significant bands in the $1307-1206 \mathrm{~cm}^{-1}$ region are representative of the presence of the pyrophosphate systems. The adsorption bands corresponding to the phosphate groups appear in the $900-1140 \mathrm{~cm}^{-1}$ region but overlap with those specific to the pullulan. However, one shoulder is present at 1139 $\mathrm{cm}^{-1}$. The disappearance of the $1720 \mathrm{~cm}^{-1}$ band, which is specific to the acetoxy group, is due to the alkaline environment in which the crosslinking reaction was performed. $\mathrm{P}-\mathrm{O}-\mathrm{C}$ bonding in the region between 970 and $1050 \mathrm{~cm}^{-1}$ can also be verified, confirming the presence of crosslinks between PVA and STMP [39]. 

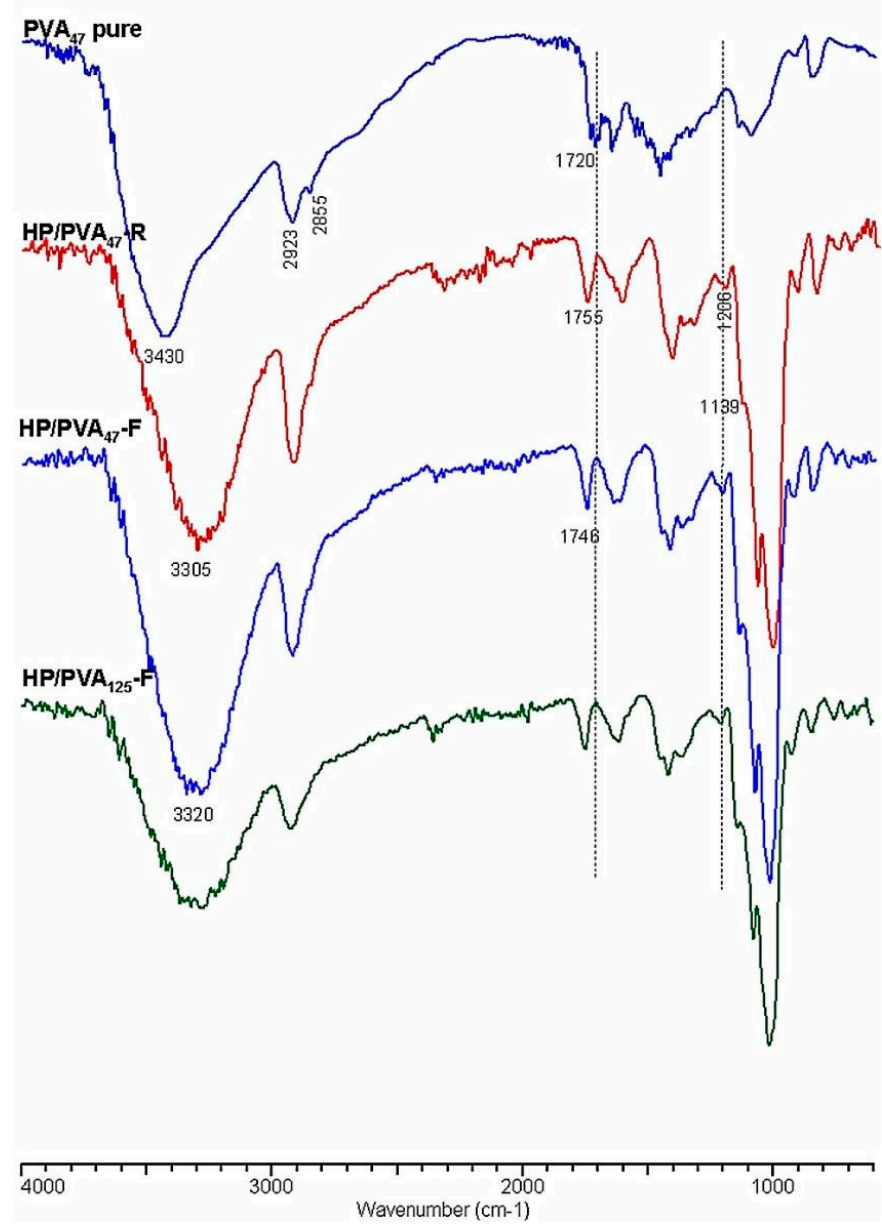

Figure 3. FTIR spectra of PVA and HP/PVA hydrogels.

The diminution of the peaks from 2935 and $2855 \mathrm{~cm}^{-1}$, corresponding to the asymmetrical and symmetrical stretching of the $\mathrm{CH}_{2}$ of PVA, suggests crystallite formation in which the mobility of these groups are retained [40].

\subsection{Swelling and Dissolution Behavior}

The swelling degree is a process influenced both by the degree of crosslinking and the electrostatic rejection between macromolecular chains.

Since hydrogels have been prepared in the present study both by chemical crosslinking at room temperature and by chemical and physical crosslinking by freezing/thawing, the swelling process is expected to be influenced mainly by the crosslinking procedure and the crosslinker itself. The presence of the crosslinker (STMP) in a higher amount in the polymeric network has two opposing effects: i) It increases the number of intermolecular bridges, reducing the swelling degree and ii) It increases the number of anionic charged groups (phosphate) in the hydrogel, generating electrostatic rejections between neighboring macromolecular chains, thus increasing the swelling.

In the case of cryogels, water can enter through the interconnected pores of the network by convection. In contrast to the cryogels, the swelling kinetics of the hydrogels are controlled by the diffusion of solvent molecules through the gel network, which is a slow process [41].

Therefore, it can be observed that HP/PVA cryogels swell less than the corresponding hydrogels. This is expected since the cryogels are formed below the freezing point of water, and by freeze/thaw cycles, a denser crosslinked network and harder hydrogels are obtained [41].

Consequently, the swelling kinetics of the two types of hydrogels are different (Figure 4A). The HP/PVA $47-\mathrm{R}$ hydrogels gradually take up to 6 hours to swell due to their high porosity and 
uniform structure of the network. On the contrary, the HP/PVA-F cryogels swell rapidly, reaching equilibrium in approximately $60 \mathrm{~min}$. It can be seen that the HP/PVA $125-\mathrm{F}$ cryogels swell more than the $\mathrm{HP} / \mathrm{PVA}_{47}-\mathrm{F}$ one. This behavior is as expected since, for the $\mathrm{HP} / \mathrm{PVA}_{125}$ preparation, we used PVA with higher molecular weight and in a smaller final concentration compared with the HP/PVA $47-\mathrm{F}$ cryogels (see Table 1). On the one hand, the lower concentration of PVA in the HP/PVA $125-\mathrm{F}$ cryogel led to a structure that was less crosslinked, with slightly larger porosity (Figure 2), which increased the equilibrium swelling [42]. Hassan and Peppas (2000) found that, for hydrogels obtained by using higher molecular weight PVA, higher volume swelling ratios are obtained due to an additional crystallization during swelling and increased mobility because of less physical crosslinking [43].
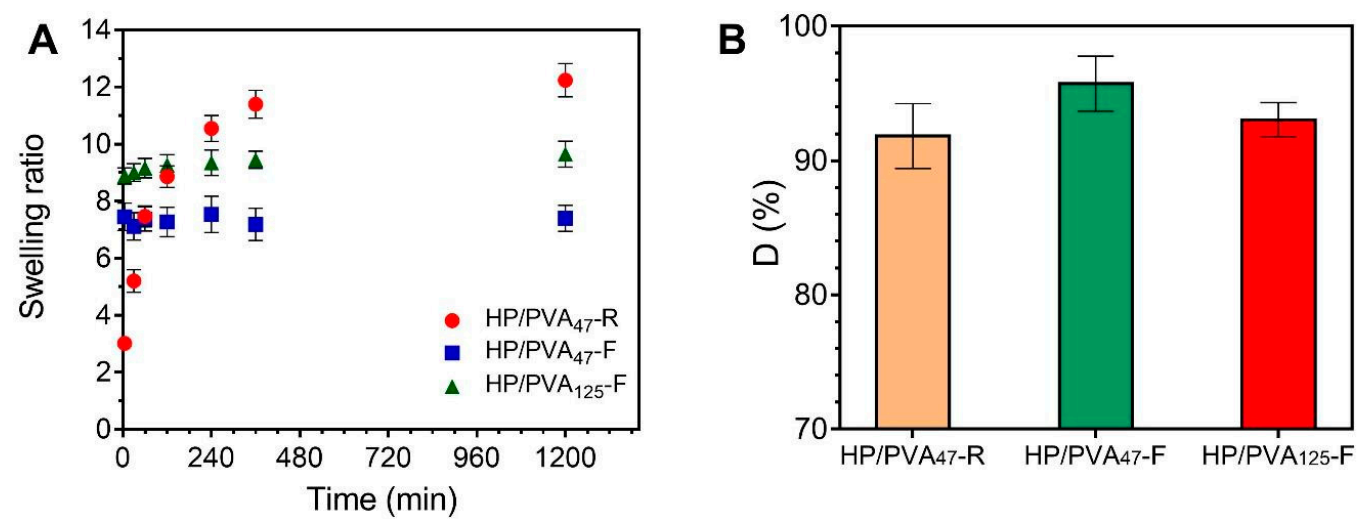

Figure 4. Swelling kinetics of HP/PVA composite hydrogels in simulated physiological conditions (PBS at $\left.37^{\circ} \mathrm{C}\right)(\mathbf{A})$ and dissolution percent in water at $23^{\circ} \mathrm{C}$ of composite hydrogels (B).

Upon placement in water for 3 days, all HP/PVA samples prepared lost between 4 and 10 percent of their structure. From the data presented in Figure 4B, it can be assumed that a more stable structure is obtained by combining the two crosslinking methods, since a smaller fraction of $\mathrm{P}$ and PVA chains that were not incorporated into the overall structure of $\mathrm{P} \mathrm{PVA}_{47}-\mathrm{F}$ hydrogel $(4 \%)$ dissolved into water compared with $\mathrm{P} / \mathrm{PVA}_{47}-\mathrm{R}$ hydrogel (8.2\%). A lower degree of PVA and P dissolution was observed with samples prepared with lower molecular weight PVA and by using higher PVA concentrations (D\% for $\mathrm{HP} / \mathrm{PVA}_{47}-\mathrm{F}<\mathrm{D} \%$ for $\mathrm{HP} / \mathrm{PVA}_{125}-\mathrm{F}$ ). Therefore, it is evident from these results that there is an increased degree of physical crosslinking associated with an increased initial PVA concentration. However, the apparent difference between the dissolution percentages of the three types of hydrogels is not significant if $\mathrm{SD}$ values are considered.

\subsection{In Vitro Degradation Studies}

Ideally, hydrogels as tissue engineering scaffolds should be degradable at a rate proportional to the formation of new tissue [42]. The degradation profiles of the HP/PVA hydrogels after 28 days (expressed as a \% weight loss) are illustrated in Figure 5. As apparent from the figure, controlled mass loss rates (less than $8 \%$ weight loss) were displayed in the HP/PVA composite cryogels $(4.83 \pm 0.5 \%$ for $\mathrm{HP} / \mathrm{PVA}_{47}-\mathrm{F}$ and $7.19 \pm 0.8 \%$ for $\mathrm{HP} / \mathrm{PVA}_{125}-\mathrm{F}$, respectively). When we compare the composite cryogels after 28 days, $\mathrm{HP} / \mathrm{PVA}_{125}-\mathrm{F}$ showed a statistically significant increase $(\mathrm{p}<0.02)$. After the same period, the degree of degradation of $\mathrm{HP} / \mathrm{PVA}_{47}-\mathrm{R}$ hydrogels was found to be $12.4 \pm 1.5 \%$, higher that for the corresponding cryogels; this hydrogel displayed a statistically significant augmentation of weight loss compared with the HP/PVA $47-\mathrm{F}(p<0.001)$ and $\mathrm{HP} / \mathrm{PVA}_{125}-\mathrm{F}(p<0.007)$ cryogels. These observations showed that the stability of the hydrogels increased by combining the two crosslinking methods. Obviously, as the pullulan concentration increased, the degradation rate increased, since only the polysaccharide is susceptible to degradation. 


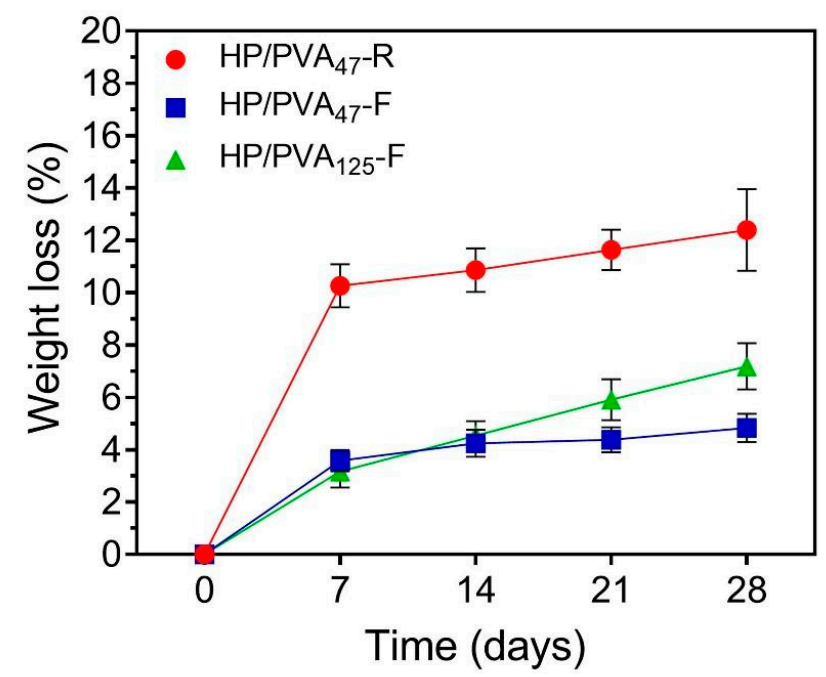

Figure 5. Weight loss profiles of HP/PVA composite hydrogels in PBS at $37^{\circ} \mathrm{C}$.

\subsection{Biocompatibility}

After 2 days of culture in standard conditions, MTT assay results indicated a good biocompatibility on all tested materials, with a slightly increased viability for $\mathrm{HP} / \mathrm{PVA}_{125}-\mathrm{F}$ when compared to $\mathrm{HP} / \mathrm{PVA}_{47}-\mathrm{F}$ and $\mathrm{HP} / \mathrm{PVA}_{47}-\mathrm{R}$ materials (Figure $6 \mathrm{~A}$ ). $\mathrm{HP} / \mathrm{PVA}_{47}-\mathrm{F}$ and $\mathrm{HP} / \mathrm{PVA}_{47}-\mathrm{R}$ had similar viability values with the control. After being in culture for 6 days, the composites started showing different levels of proliferation. The control system showed a statistically significant higher proliferation $(p<0.01)$ at 6 days in comparison to the level registered at 2 days. The same results were observed for cells cultured on $\mathrm{HP} / \mathrm{PVA}_{47}-\mathrm{F}$. HP/PVA $125-\mathrm{F}$, which showed a better predisposition for increased viability at first, at 6 days displayed a statistically significant elevation of proliferation $(p<0.001)$. When comparing the proliferation at 6 days on all three tested composites, $\mathrm{HP} / \mathrm{PVA}_{125}-\mathrm{F}$ showed the highest statistically significant increase $(p<0.01)$. Furthermore, a slight tendency of increased viability, with no statistical significance, was noticed for cells cultured on $\mathrm{HP} / \mathrm{PVA}_{47}-\mathrm{F}$ material in comparison with the HP/PVA $47-\mathrm{R}$ scaffold. By supporting cell proliferation the best, $\mathrm{HP} / \mathrm{PVA}_{125}-\mathrm{F}$ indicated that PVA with P could promote and stimulate cell viability and proliferation.

Composites' cytotoxicity was assessed by LDH assay in order to quantitate the level of LDH enzyme released in the cell culture media. Results showed that after 2 days of culture, the scaffolds exhibited similar cytotoxicity compared to the control (Figure 6B). At 6 days, the cytotoxicity of the materials slightly increased but remained at approximately the same level as the control. No statistically significant difference was found between the LDH levels released by the tested composites, indicating that the combination of PVA with P does not exert an important cytotoxic effect on the cellular component.

Confocal microscopy was used to evaluate Live/Dead staining, which was performed in order to visualize cell dispersion inside the materials and the proportion of live (green) and dead (red) cells. The results indicated a consistency with the MTT and LDH assays, because, overall, the number of viable cells was much higher than the number of dead cells. Additionally, visualization by confocal microscopy allowed the observation of cell morphology, which was characteristic for the three-dimensional culture systems (Figure 6C). After 2 days of culture in standard conditions, a high proportion of live cells was observed on all scaffolds. Furthermore, cells were evenly distributed on the control, $\mathrm{HP} / \mathrm{PVA}_{47}-\mathrm{F}, \mathrm{HP} / \mathrm{PVA}_{125}-\mathrm{F}$, and HP/PVA $47-\mathrm{R}$. After 6 days of being in contact with the composites, the highest number of viable cells (Figure 6) was established on $\mathrm{HP} / \mathrm{PVA}_{125}-\mathrm{F}$ when compared to the control and to the HP/PVA $47-\mathrm{F}$ and $\mathrm{HP} / \mathrm{PVA}_{47}-\mathrm{R}$ materials. Even though, at 2 days, $\mathrm{HP} / \mathrm{PVA}_{47}-\mathrm{R}$ had a similar number of live cells to the rest of the composites, after 6 days of culture the percentage of dead cells increased compared to the other composites, indicating that its composition has negative effects on cell behavior. 
A

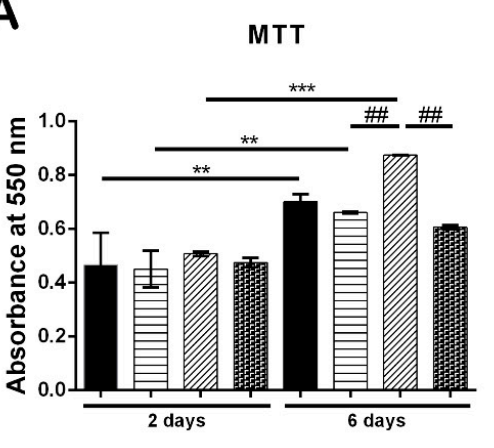

B

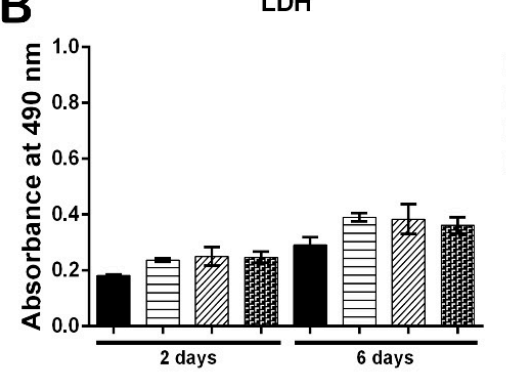

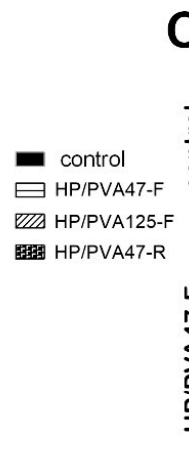

C days
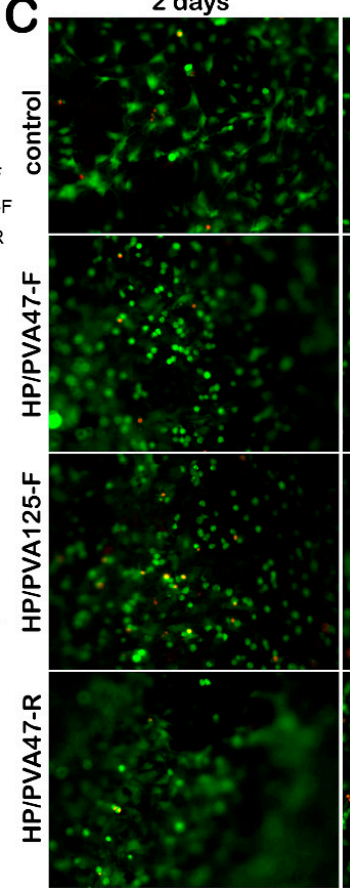

6 days

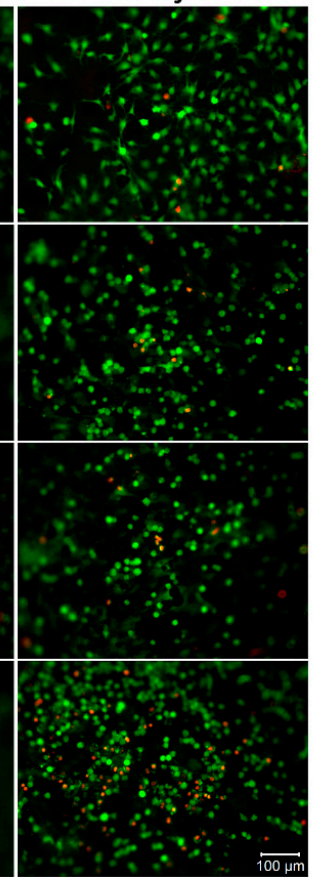

Figure 6. Quantitative evaluation of cell viability and proliferation after 2 and 6 days of culture, using MTT assay (A); Quantitative evaluation of the material's cytotoxicity after 2 and 6 days of culture, using LDH assay (B); Confocal microscopy displaying live (green) and dead (red) cells after 2 and 6 days of culture $(\mathbf{C})$; scale bar $100 \mu \mathrm{m}$.

\subsection{Adipogenic Differentiation Assessment}

\subsubsection{Adipogenic Marker Perilipin Gene Expression Analysis}

Evaluation of perilipin was assessed in order to investigate the adipogenic differentiation of cells, since perilipin is a late differentiation marker. Consequently, its level was expected to be low seven days after adipogenesis induction. After 7 days of differentiation, perilipin gene expression for cells cultivated on $\mathrm{HP} / \mathrm{PVA}_{47}-\mathrm{F}$ and $\mathrm{HP} / \mathrm{PVA}_{125}-\mathrm{F}$ materials was similar, but for cells cultivated on $\mathrm{HP} / \mathrm{PVA}_{47}-\mathrm{R}$ it was slightly lower, with no statistical significance (Figure 7A). After cells were kept in culture with a differentiation medium for 21 days and then compared to the results obtained at 7 days, perilipin gene expression was found to be significantly higher for cells cultivated on all tested materials (overall, approximately 3 times higher). In the case of cells differentiated in contact with $\mathrm{HP} / \mathrm{PVA}_{125}-\mathrm{F}$ for 21 days, a statistically significant increased expression $(p<0.001)$ was found when compared to perilipin levels at 7 days and to the other composites. The same results were observed for cells differentiated on the control system $(p<0.001)$, with perilipin being highly expressed after 21 days of induced adipogenesis. Perilipin expression was the highest on the control system because the cells seeded on the tissue culture plastic system undergo adipogenic differentiation at a faster rate than the ones cultivated on materials. Cells cultivated in contact with $\mathrm{HP} / \mathrm{PVA}_{47}-\mathrm{F}$ and $\mathrm{HP} / \mathrm{PVA}_{47}-\mathrm{R}$ for 21 days, expressed perilipin in a statistically significant manner $(p<0.01)$. 
A

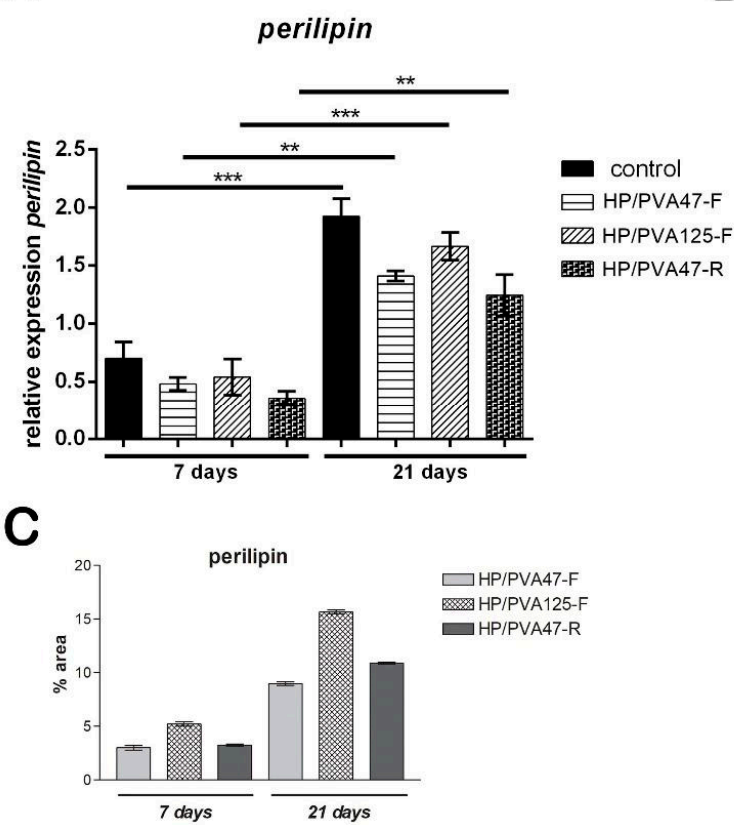

B

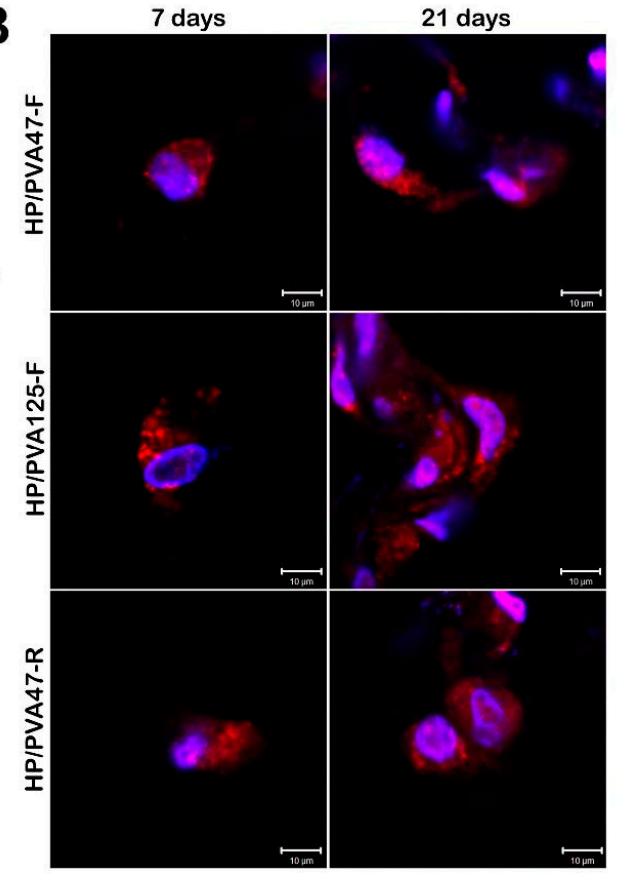

Figure 7. Evaluation of perilipin gene expression after 7 and 21 days of adipogenic differentiation (A); Evaluation of perilipin protein expression after 7 and 21 days of adipogenic differentiation by confocal microscopy (B); scale bar $10 \mu \mathrm{m}$; quantification of perilpin levels of protein expression (C).

\subsubsection{Adipogenic Marker Perilipin Protein Expression}

Similar to the gene expression, protein expression of adipogenic marker perilipin was evaluated at 7 and 21 days of adipogenic differentiation. Perilipin is a late differentiation marker, as its expression is higher when pre-adipocytes are fully differentiated into adipocytes. Confocal microscopy indicated that perilipin was present in cells cultured in contact with all tested materials after 7 days (Figure 7B). Perilipin expression was detected in cells cultured in contact with $\mathrm{HP} / \mathrm{PVA}_{47}-\mathrm{F}$ after 7 days, but it was highly expressed after 21 days of differentiation. The same results were obtained for HP/PVA $47-\mathrm{R}$, where perilipin was highly expressed after cells were kept in contact with the material for 21 days. These two scaffolds, $\mathrm{HP} / \mathrm{PVA}_{47}-\mathrm{F}$ and $\mathrm{HP} / \mathrm{PVA}_{47}-\mathrm{R}$, presented a comparable expression of perilipin, whereas the most significant expression was visualized in cells cultured in contact with $\mathrm{HP} / \mathrm{PVA}_{125}-\mathrm{F}$ after 21 days. When performing the quantification of the area and the intensity of red-labeled perilipin by Image J, a clear higher expression of perilipin was obtained for HP/PVA125-F than on the other compositions, confirming that this scaffold supported adipogenesis with the highest efficiency.

\section{Conclusions}

Porous composite pullulan/PVA hydrogels and cryogels were successfully prepared using a combining chemical and physical crosslinking at room temperature method or by a freeze-thawing method. The materials described in this study have shown good swelling capacity, as well as excellent stability against dissolution in water or degradation in PBS pH 7.4 at $37^{\circ} \mathrm{C}$. The cryogels also demonstrated very good biocompatibility, which makes them promising materials for tissue engineering because of their adipogenic differentiation ability.

It must be underlined that the excellent biocompatibility of PVA and P, combined with a mild procedure and the avoidance of any toxic crosslinking molecules, recommend the use of these hydrogels in biomedical applications.

Author Contributions: Conceptualization, G.G.P. and S.D.; methodology, S.D.; validation, I.S. and G.F; investigation, I.S.; writing-original draft preparation, I.S. and M.C.; writing-review and editing, G.G.P. and L.M.; supervision, M.A.; project administration, M.A. 
Funding: The authors acknowledge the financial support of this research through the project, Partnerships for Knowledge Transfer in the Field of Polymer Materials Used in Biomedical Engineering, ID_40_443, Contract no. 86/8.09.2016, MY SMIS 105689, co-financed by the European Regional Development Fund by the Competitiveness Operational Program, 2014-2020, Axis 1 Research, Technological Development and Innovation in support of economic competitiveness and business development, Action 1.2.3 Knowledge Transfer Partnerships. This work was (partially) supported by a grant from the Romanian Ministry of Research and Innovation, project number PN-III-P1-1.2-PCCDI-2017-0629/contract no. 43PCCDI/2018.

Conflicts of Interest: The authors declare no conflict of interest.

\section{References}

1. Broder, K.W.; Cohen, S.R. An overview of permanent and semipermanent fillers. Plast. Reconstr. Surg. 2006, 118, 7S-14S. [CrossRef] [PubMed]

2. Patrick, C.W., Jr. Tissue engineering strategies for adipose tissue repair. Anat. Rec. 2001, 263, 361-366. [CrossRef] [PubMed]

3. Van Nieuwenhove, I.; Tytgat, L.; Ryx, M.; Blondeel, P.; Stillaert, F.; Thienpont, H.; Van Vlierberghe, S. Soft tissue fillers for adipose tissue regeneration: From hydrogel development toward clinical applications. Acta Biomater. 2017, 63, 37-49. [CrossRef] [PubMed]

4. Volz, A.C.; Huber, B.; Kluger, P.J. Adipose-derived stem cell differentiation as a basic tool for vascularized adipose tissue engineering. Differentiation 2016, 92, 52-64. [CrossRef] [PubMed]

5. Vallée, M.; Côté, J.F.; Fradette, J. Adipose tissue engineering: Taking advantage of the properties of human adipose-derived stem/stromal cells. Pathol. Biol. 2009, 57, 309-317. [CrossRef] [PubMed]

6. Rojo, L.; Vasquez, B.; Roman, J.S. Biomaterials for Scaffolds: Synthetic polymers. Scaffolds Tissue Eng. Biol. Des. Mater. Fabr. 2014, 263-300. [CrossRef]

7. Singh, M.R.; Patel, S.; Singh, D. Natural polymer-based hydrogels as scaffolds for tissue engineering. Nanobiomater. Soft Tissue Eng. 2016, 5, 231-260.

8. Bacakova, L.; Novotna, K.; Parizek, M. Polysaccharides as Cell Carriers for Tissue Engineering: The Use of Cellulose in Vascular Wall Reconstruction. Physiol. Res. 2014, 63, S29-S47.

9. Lavegne, M.; Derkaoui, M.; Delmau, C.; Letourneur, D.; Uzan, G.; Le Visage, C. Porous polysaccharide based scaffolds for human endothelial progenitor cells. Macromol. Biosci. 2012, 12, 901-910. [CrossRef]

10. Fricain, J.C.; Schlaubitz, S.; Le Visage, C.; Arnault, I.; Derkaoui, S.M.; Siadous, R.; Catros, S.; Lalande, C.; Bareille, R.; Renard, M.; et al. A nano-hydroxyapatite-pullulan/dextran polysaccharide composite macroporous material for bone tissue engineering. Biomaterials 2013, 34, 2947-2959. [CrossRef]

11. Wong, V.W.; Rustad, K.C.; Galvez, M.G.; Neofytou, E.; Glotzbach, J.P.; Januszyk, M.; Major, M.R.; Sorkin, M.; Longaker, M.T.; Rajadas, J.; et al. Engineered Pullulan-Collagen Composite Dermal Hydrogels Improve Early Cutaneous Wound Healing. Tissue Eng. A 2011, 17, 631-644. [CrossRef]

12. Fathi, E.; Atyabi, N.; Imani, M.; Alinejad, Z. Physically crosslinked polyvinyl alcohol-dextran blend xerogels: Morphology and thermal behavior. Carbohydr. Polym. 2011, 84, 145-152. [CrossRef]

13. Alexandre, N.; Ribeiro, J.; Gärtner, A.; Pereira, T.; Amorim, I.; Fragoso, J.; Lopes, A.; Fernandes, J.; Costa, E.; Santos-Silva, A.; et al. Biocompatibility and hemocompatibility of polyvinyl alcohol hydrogel used for vascular grafting-In vitro and in vivo studies. J. Biomed. Mater. Res. A 2014, 102, 4262-4275.

14. Kenawy, E.R.; Kamoun, E.A.; Eldin, M.S.M.; El-Meligy, M.A. Physically crosslinked poly(vinyl alcohol)-hydroxyethyl starch blend hydrogel membranes: Synthesis and characterization for biomedical applications. Arab. J. Chem. 2014, 7, 372-380. [CrossRef]

15. Chen, C.; Liu, L.; Huang, T.; Wang, Q.; Fang, Y.E. Bubble template fabrication of chitosan/poly(vinyl alcohol) sponges for wound dressing applications. Int. J. Biol. Macromol. 2013, 62, 188-193. [CrossRef]

16. Gomez, C.; Luna-Barcenas, G.; Ibarra, C.; Velasquillo, C. Biocompatibility of Human Auricular Chondrocytes Cultured onto a Chitosan/Polyvynil Alcohol/Epichlorohydrin-Based Hydrogel for Tissue Engineering Application. Int. J. Morphol. 2014, 32, 1347-1356.

17. Bichara, D.A.; Zhao, X.; Hwang, N.S.; Bodugoz-Senturk, H.; Yaremchuk, M.J.; Randolph, M.A.; Muratoglu, O.K. Porous Poly(vinyl alcohol)-Alginate Gel Hybrid Construct for Neocartilage Formation Using Human Nasoseptal Cells. J. Surg. Res. 2010, 163, 331-336. [CrossRef] 
18. Chhatri, A.; Bajpai, J.; Bajpai, A.K.; Sandhu, S.S.; Jain, N.; Biswas, J. Cryogenic fabrication of savlon loaded macroporous blends of alginate and polyvinyl alcohol (PVA). Swelling, deswelling and antibacterial behaviors. J. Carbohydr. Polym. 2011, 83, 876-882. [CrossRef]

19. Thankam, F.G.; Muthu, J.; Sankar, V.; Gopal, R.K. Growth and survival of cells in biosynthetic poly vinyl alcohol-alginate IPN hydrogels for cardiac applications. Colloids Surf. B Biointerfaces 2013, 107, 137-145. [CrossRef]

20. Vrana, N.E.; Cahill, P.A.; McGuinness, G.B. Endothelialization of PVA/gelatin cryogels for vascular tissue engineering: Effect of disturbed shear stress conditions. J. Biomed. Mater. Res. A 2010, 94, 1080-1090. [CrossRef]

21. Bao, T.Q.; Franco, R.A.; Lee, B.T. Material properties and characterizations of cross-linked electro-spinning raspberry ketone incorporated polyvinyl alcohol/gelatin fibrous scaffolds. J. Biomed. Sci. Eng. 2011, 4, 1-9. [CrossRef]

22. Subramanian, U.M.; Kumar, S.V.; Nagiah, N.; Sivagnanam, U.T. Fabrication of Polyvinyl Alcohol-Polyvinylpyrrolidone Blend Scaffolds via Electrospinning for Tissue Engineering Applications. Int. J. Polym. Mater. Polym. Biomater. 2014, 63, 476-485. [CrossRef]

23. Wan, W.K.; Campbell, G.; Zhang, Z.F.; Hui, A.J.; Boughner, D.R. Optimizing the tensile properties of polyvinyl alcohol hydrogel for the construction of a bioprosthetic heart valve stent. J. Biomed. Mater. Res. 2002, 63, 854-861. [CrossRef]

24. Saavedra, Y.G.; Mateescu, M.A.; Averill-Bates, D.A.; Denizeau, F. Polyvinylalcohol three-dimensional matrices for improved long-term dynamic culture of hepatocytes. J. Biomed. Mater. Res. Part A 2003, 66, 562-570. [CrossRef]

25. Kumar, A.; Han, S.S. PVA-based hydrogels for tissue engineering: A review. Int. J. Polym. Mater. Polym. Biomater. 2016, 66, 159-182. [CrossRef]

26. Sztalryd, C.; Brasaemle, D.L. The perilipin family of lipid droplet proteins: Gatekeepers of intracellular lipolysis. Biochim. Biophys. Acta, Mol. Cell. Biol. Lipids 2017, 1862, 1221-1232. [CrossRef]

27. Sawada, T.; Miyoshi, H.; Shimada, K.; Suzuki, A.; Okamatsu-Ogura, Y.; Perfield, J.W., II; Kondo, T.; Nagai, S.; Shimizu, C.; Yoshioka, N.; et al. Perilipin overexpression in white adipose tissue induces a brown fat-like phenotype. PLOS ONE 2010, 5, e14006. [CrossRef]

28. Wang, Y.; Sullivan, S.; Trujillo, M.; Lee, M.J.; Schneider, S.H.; Brolin, R.E.; Kang, Y.H.; Werber, Y.; Greenberg, A.S.; Fried, S.K. Perilipin expression in human adipose tissues: Effects of severe obesity, gender, and depot. Obes. Res. 2003, 11, 930-936. [CrossRef]

29. Mocanu, G.; Mihai, D.; Picton, L.; Le Cerf, D.; Muller, G. Associative pullulan gels and their interaction with biological active substances. J. Control. Release 2002, 83, 41-51. [CrossRef]

30. Lack, S.; Dulong, V.; Le Cerf, D.; Picton, L.; Argillier, J.F.; Muller, G. Hydrogels based on pullulan crosslinked with sodium trimetaphosphate (STMP): Rheological study. Polym. Bull. 2004, 52, 429-436. [CrossRef]

31. Leone, G.; Consumi, M.; Aggravi, M.; Donati, A.; Lamponi, S.; Magnani, A. PVA/STMP based hydrogels as potential substitutes of human vitreous. J. Mater. Sci. Mater. Med. 2010, 21, 2491-2500. [CrossRef] [PubMed]

32. Peppas, N.A.; Merrill, E.W. Development of semicrystalline poly(vinyl alcohol) hydrogels for biomedical applications. J. Biomed. Mater. Res 1977, 1, 423-434. [CrossRef] [PubMed]

33. Abdel-Mohsen, A.M.; Aly, A.S.; Hrdina, R.; Montaser, A.S.; Hebeish, A. Synthesis of PVA/Chitosan Hydrogels for Biomedical Application. J. Polym. Environ. 2011, 19, 1005-1012. [CrossRef]

34. Constantin, M.; Fundueanu, G.; Bortolotti, F.; Cortesi, R.; Ascenzi, P.; Menegatti, E. A novel multicompartimental system based on aminated poly(vinyl alcohol) microspheres/succinoylated pullulan microspheres for oral delivery of anionic drugs. Int. J. Pharm. 2007, 330, 129-137. [CrossRef] [PubMed]

35. Zolotarsky, Y.; O'Halloran, D. Pullulan and polyvinyl alcohol based film forming compositions. U.S. Patent 20030086954 A1, 8 May 2003.

36. Chaouat, M.; Le Visage, C.; Baille, W.E.; Escoubet, B.; Chaubet, F.; Mateescu, M.A.; Letourneur, D.A. Novel Cross-linked Poly(vinyl alcohol) (PVA) for Vascular Grafts. Adv. Funct. Mater. 2008, 18, 2855-2861. [CrossRef]

37. Bejenariu, A.; Popa, M.; Dulong, V.; Picton, L.; Le Cerf, D. Trisodium trimetaphosphate crosslinked xanthan networks: Synthesis, swelling, loading and releasing behavior. Polym. Bull. 2009, 62, 525-538. [CrossRef]

38. Costa-Júnior, E.S.; Barbosa-Stancioli, E.F.; Mansur, A.A.P.; Vasconcelos, W.L.; Mansur, H.S. Preparation and characterization of chitosan/poly(vinylalcohol) chemically crosslinked blends for biomedical applications. Carbohydr. Polym. 2009, 76, 472-481. [CrossRef] 
39. Morandim-Giannetti, A.A.; Silva, R.C.; Magalhães, O., Jr.; Schor, P.; Bersanetti, P.A. Conditions for obtaining polyvinyl alcohol/trisodium trimetaphosphate hydrogels as vitreous humor substitute. J. Biomed. Mater. Res. 2016, 104, 1386-1395. [CrossRef]

40. Bajpai, A.K.; Saini, R. Preparation and characterization of biocompatible spongy cryogels of poly(vinyl alcohol)-gelatin and study of water sorption behavior. Polym. Int. 2005, 54, 1233-1242. [CrossRef]

41. Lozinsky, V.I.; Galaev, I.Y.; Plieva, F.M.; Savina, I.N.; Jungvid, H.; Mattissoon, B. Polymeric cryogels as promising materials of biotechnological interest. Trends Biotechnol. 2003, 21, 445-451. [CrossRef]

42. Hassan, C.; Peppas, N. Structure and morphology of freeze/thawed PVA hydrogels. Macromolecules 2000, 33, 2472-2479. [CrossRef]

43. Hassan, C.M.; Ward, J.H.; Peppas, N.A. Modeling of crystal dissolution of poly(vinyl alcohol) gels produced by freezing/thawing processes. Polymer 2000, 41, 6729-6739. [CrossRef]

(C) 2019 by the authors. Licensee MDPI, Basel, Switzerland. This article is an open access article distributed under the terms and conditions of the Creative Commons Attribution (CC BY) license (http://creativecommons.org/licenses/by/4.0/). 